\section{Microscopy Coming Events}

\section{6}

Neuroscience 2016

November 12-16, 2016

San Diego, CA

www.sfn.org

Laboratory Diagnosis of Haematological Malignancies

November 16, 2016

London, UK

www.rms.org.uk/discover-engage/eventcalendar/

laboratory-diagnosis-2016.html

2016 MRS Fall Meeting \& Exhibit

November 27-December 2, 2016

Boston, MA

www.mrs.org/fall2016

American Society for Cell Biology (ASCB) 2016 Annual Meeting

December 3-7, 2016

San Francisco, CA

http://ascb.org/future-ascb-annual-meetings

MSSA2016: Microscopy Society of Southern Africa Annual Conference

December 5-9, 2016

Port Elizabeth, South Africa

www.mssa2016.co.za

\section{7}

AMAS XIV - 14th Australian Microbeam

Biennial Symposium

February 6-10, 2017

Brisbane, Australia

http://microscopy.org.au/amas/

Microscopy \& Microanalysis 2017

August 6-10, 2017

St. Louis, MO

www.microscopy.org

\section{8}

Microscopy \& Microanalysis 2018

August 5-9, 2018

Baltimore, MD

www.microscopy.org

\section{9}

Microscopy \& Microanalysis 2019

August 4-8, 2019

Portland, OR

www.microscopy.org

\section{0}

Microscopy \& Microanalysis 2020

August 2-6, 2020

Milwaukee, WI

www.microscopy.org

\section{1}

Microscopy \& Microanalysis 2021

August 1-5, 2021

Pittsburgh, PA

www.microscopy.org

More Meetings and Courses

Check the complete calendar near the back of this magazine.

\title{
An Underwater Microscope
}

\author{
Stephen W. Carmichael \\ Mayo Clinic, Rochester, MN 55905 \\ carmichael.stephen@mayo.edu
}

Approximately three-quarters of the Earth's surface is covered by oceans. In spite of the enormous size and importance of this ecosystem, we still have much to learn about the biologic systems at play in the ocean. These shortcomings include events that occur at microscopic levels. A major limiting factor is the necessity of studying microscopic events in the laboratory where simulated marine environments are only approximations. A microscope that can be used in the ocean by human scientists could go a long way to fill in this void. Such a microscope has been developed recently by Andrew Mullen, Tali Treibitz, Paul Roberts, Emily Kelly, Rael Horwitz, Jennifer Smith, and Jules Jaffe [1]. They have labeled this exciting instrument the Benthic Underwater Microscope (BUM), and it promises to fill the distinct need to make non-invasive observations of important environmental processes under natural conditions.

The BUM is an imaging system that provides the first in situ underwater observations of benthic environments at nearly micrometer resolution. This diver-deployed portable microscope can visualize spatial phenomena in marine environments such as coral reefs and kelp forests. In addition, temporal resolution is achieved with extended time-series recordings lasting several hours. This can reveal gradual or periodic activities and processes, allowing for studies of individual coral polyps and

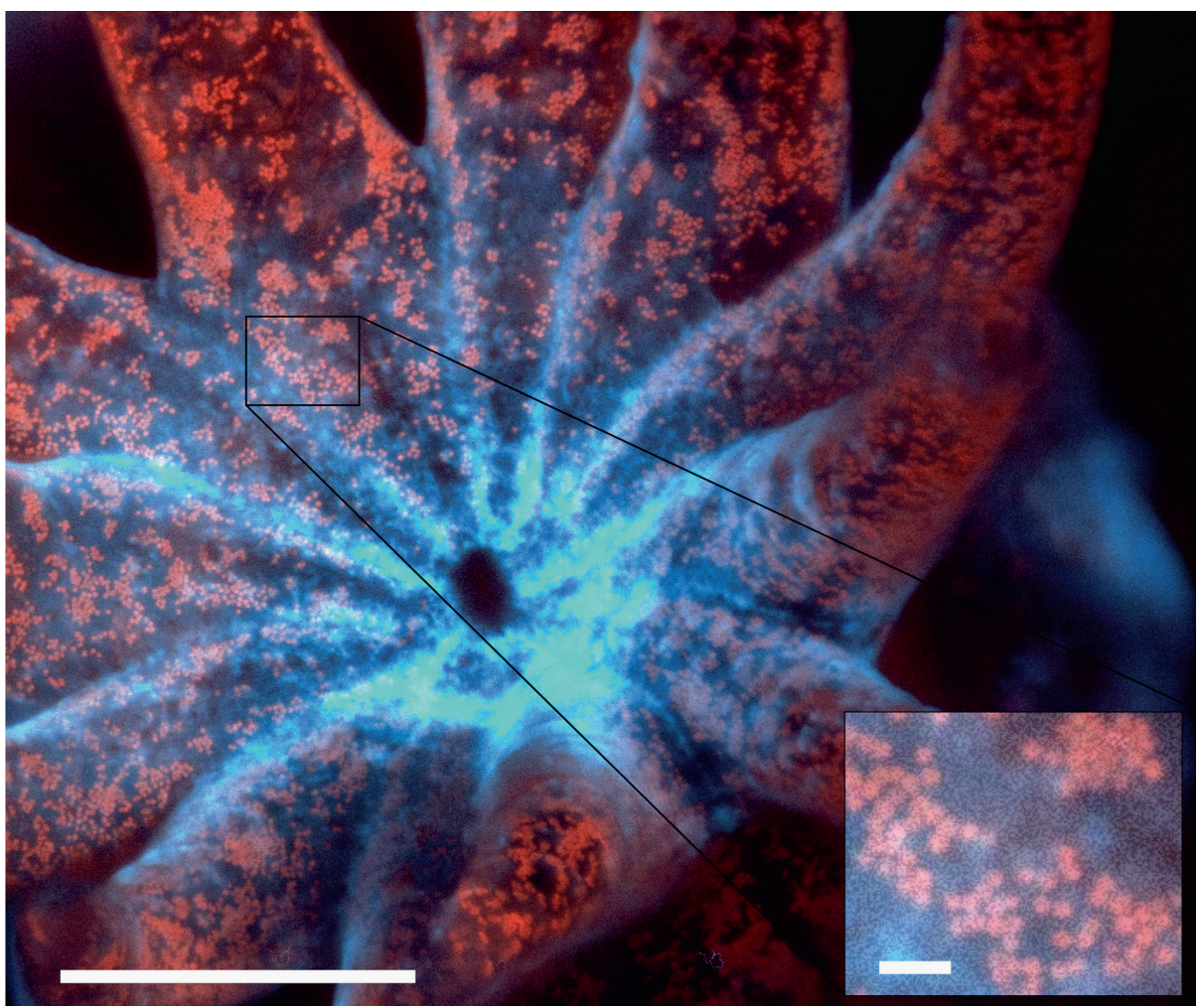

Figure 1: Fluorescent image of the coral Pocillopora taken in a lab aquarium using a $5 \times$ objective. Individual zooxanthellae $(\sim 6-13 \mu \mathrm{m}$ in size) can be seen emitting red fluorescence from their chlorophyll. Image is a composite focus stack. Main figure scale bar $=500 \mu \mathrm{m}$. Inset scale bar $=50 \mu \mathrm{m}$. Image credit: Jaffe Lab for Underwater Imaging, Scripps Institution of Oceanography at UC San Diego. 


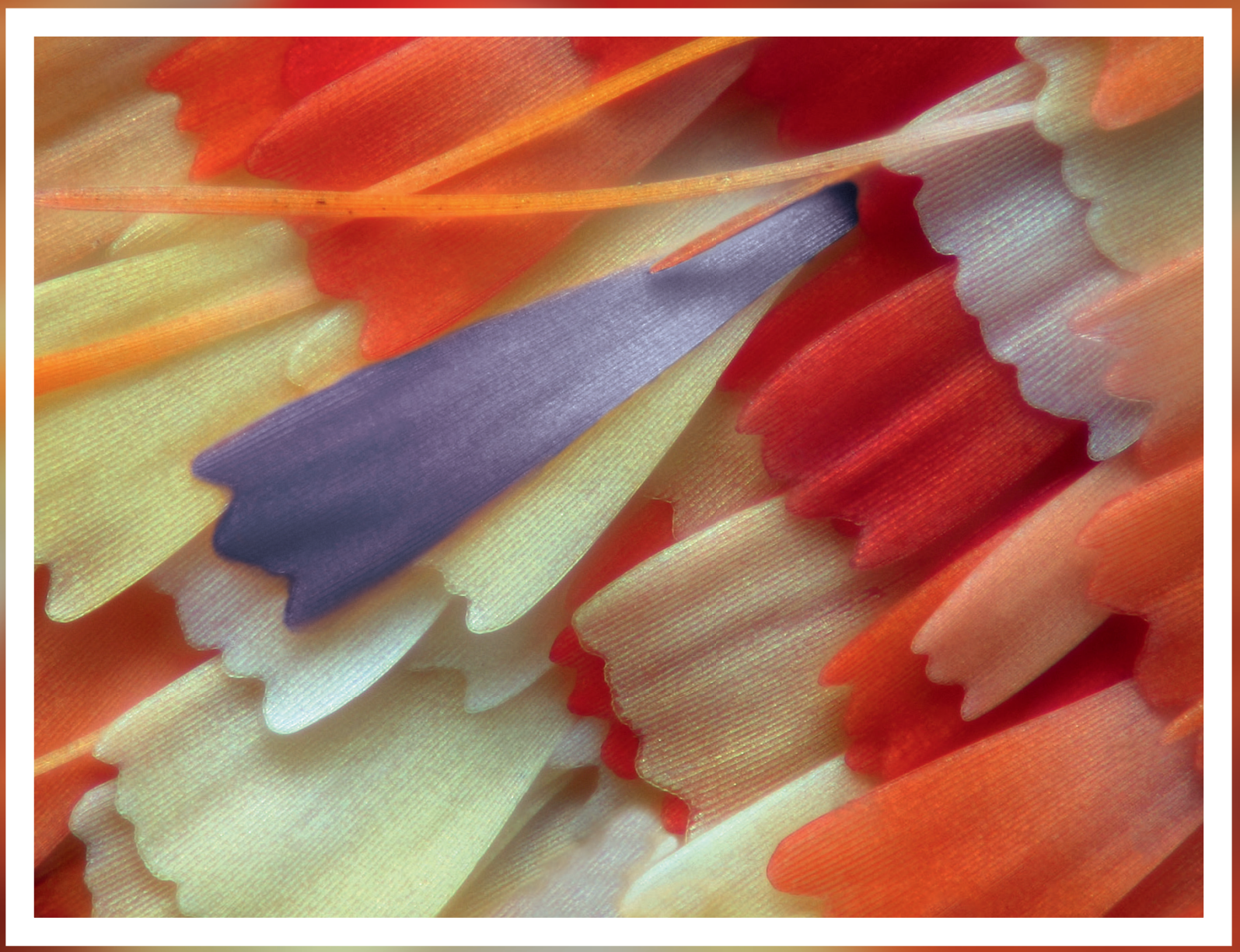

\section{BIG DISCOVERIES IN SMALL DETAILS. WE GET THE PICTURE.}

\section{THE BASLER POWERPACK FOR MICROSCOPY DELIVERS EVERYTHING YOU NEED FOR DYNAMIC MICROSCOPIC IMAGING IN A BUNDLED SOLUTION TAILORED TO YOUR EXACT SPECIFICATIONS.}

Basler has been developing superb imaging technology for more than 25 years. Now, we're using our history of innovation to drive future trends of microscopy. Introducing the Basler PowerPack for Microscopy - an accurate, affordable bundle of microscopy components that deliver superior images, premier performance and precise results. It can be utilized for applications such as education, biomedical or life science, as well as diagnostics. Basler is giving you yet another premium product at an exceptional value.

Think you know the object in focus? Test yourself at baslerweb.com/MPP.

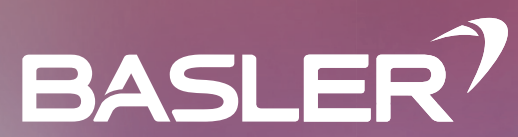

the power of sight

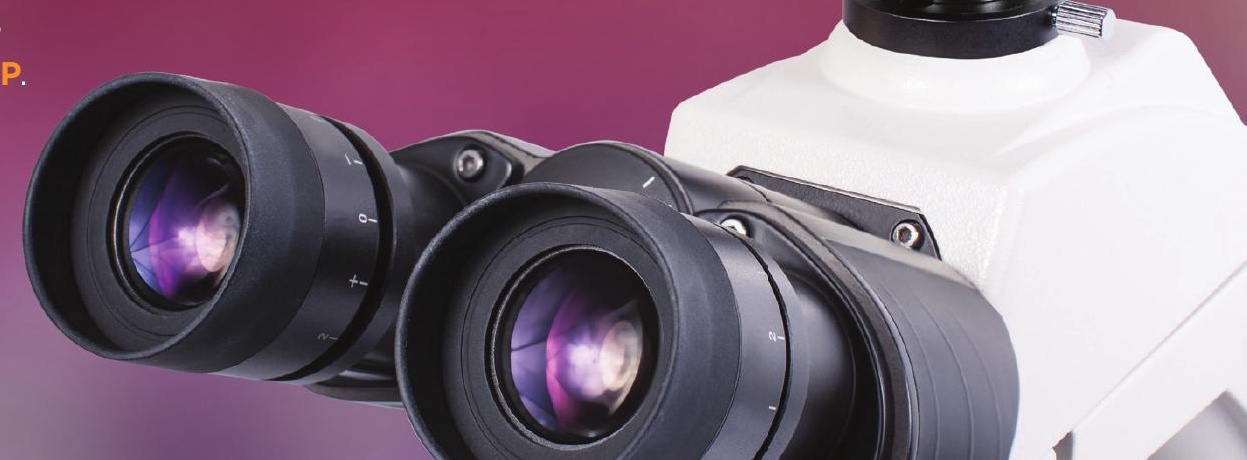


the behavior of other animals. These impressive capabilities allow both temporal and spatial analysis of ecologically significant phenomena at scales never before seen in the marine environment.

Key challenges in the design of the BUM were overcome through the use of a microscope objective with a long working distance, an electrically tunable lens (ETL) that changes shape to achieve rapid focusing. Focused reflectance illumination is provided by light emitting diodes (LEDs). The desired resolving power requires a high numerical aperture of the objective lens that results in a shallow depth of field. The ETL consists of a flexible polymer encasing an optical fluid. An integrated actuator exerts a variable pressure to rapidly change the lens curvature and focal length on a millisecond time scale. This provides a compact means to bring the subject of interest into precise focus, which is a principle challenge in benthic underwater microscopy. The ETL rapidly scans the focal plane of the optical system, and the frames are then combined using imageprocessing techniques commonly known as focus stacking. Whereas the $3 \times$ and $5 \times$ microscope objective lenses provide narrow depths of field $(34 \mu \mathrm{m}$ and $16 \mu \mathrm{m}$, respectively), the ETL yields an apparent focus over large depths, $18.4 \mathrm{~mm}$ and $6.9 \mathrm{~mm}$, respectively. The ring of LEDs around the lens provides the high-intensity light required for brief reflectance illumination without disturbing the environment.

Several observations were made by Mullen et al. that proved the usefulness of their optical system. For example, images of live coral polyps in the ocean reveal the distribution and discrimination of individual symbiotic single-celled dinoflagellates, commonly known as zooxanthellae, living inside the coral. With this imaging capability they examined corals experiencing varying levels of bleaching (which is caused by expulsion of zooxanthellae) and checked for the presence of remaining symbionts. Fluorescence imaging was conducted with the microscope in laboratory aquariums by equipping the instrument with blue LEDs combined with a filter in the imaging system to further enhance observations. These and many other studies demonstrated the ability of the BUM to collect ecologically significant spatial and temporal data that can be used for quantitative analysis.

Mullen et al. pointed out that the BUM offers a platform for technology development to facilitate future studies. This technological breakthrough promises to bring laboratory research into the ocean. Such an in situ viewpoint enables novel and important investigations on basic marine research and will provide the means to connect theoretical lab work to the natural environment!

\section{References}

[1] A.D. Mullen et al., DOI 10.1038/ncomms12093 (Nature Communications, 2016).

[2] The author gratefully acknowledges Andrew Mullen and Dr. Jules Jaffe for reviewing this article.

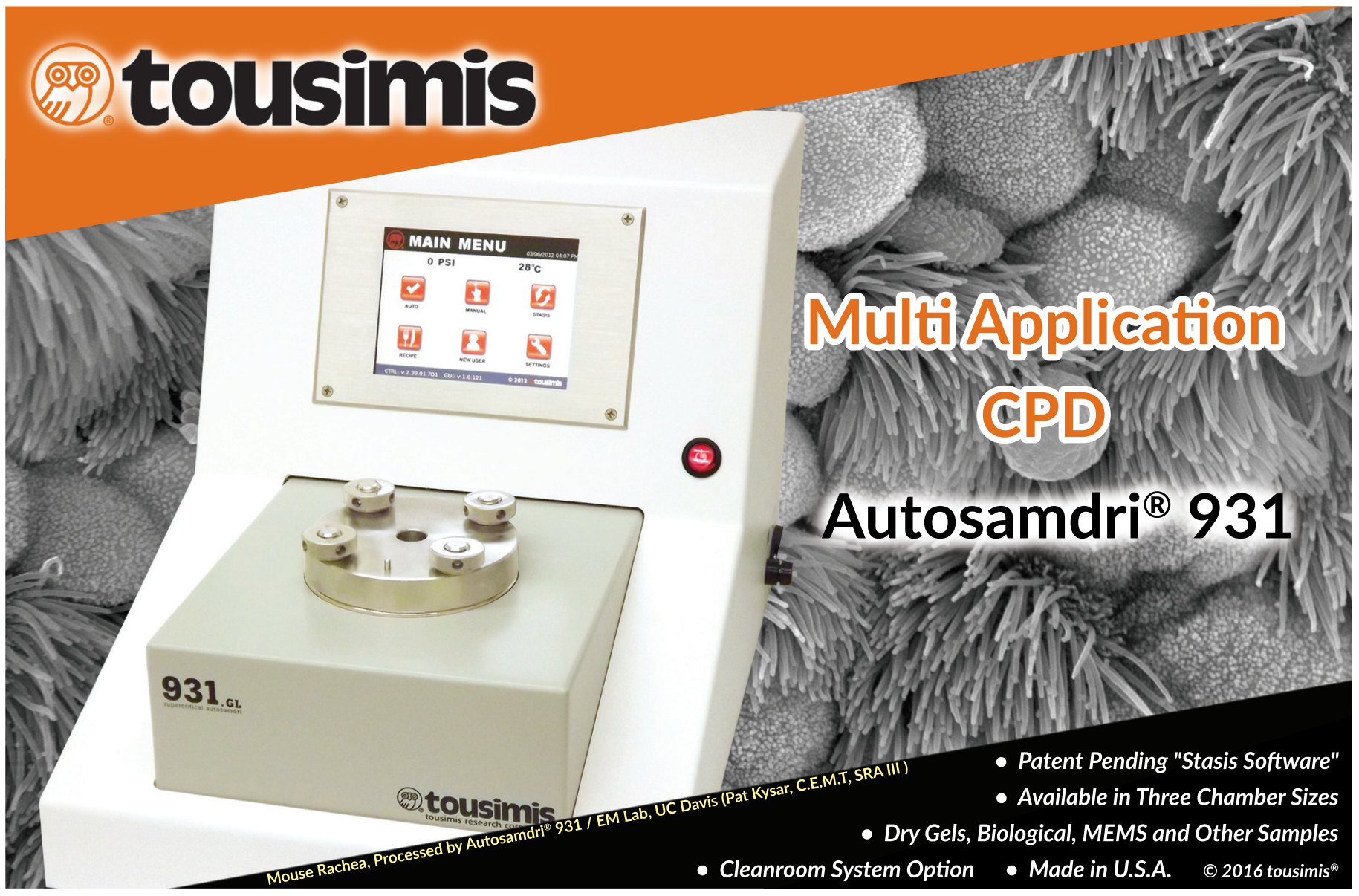




\section{The Swiss Army Knife of Microscopy}

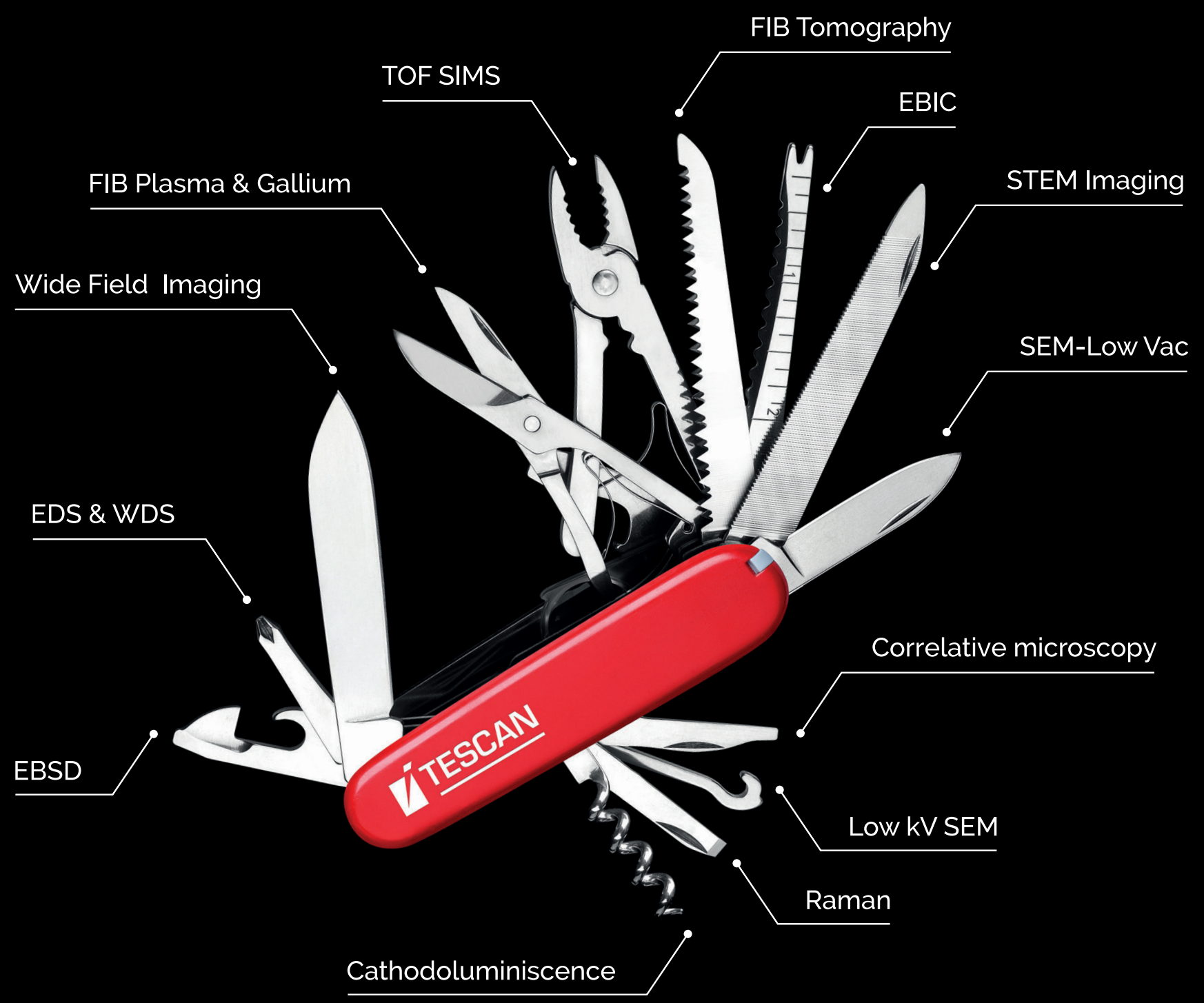

\section{Always have the right tool on hand!}

